\title{
Language and Content in Context: Toward a Social Ecology of Language in Immigrant Education
}

Laura Ho

For many adult immigrants to Canada and other countries, learning a new language may form only a single aspect of much more immediate projects of educational and personal adaptation. In acknowledging the broader context of their work, however, how can language educators begin to conceptualize the relationships between language and content teaching in ways which are responsive to the dynamic characteristics of both individuals and the community?

This article examines the social and political context of the language and content issue and introduces an environmental framework which facilitates analysis of the shape of an approach relative to its instructional intent and its situation within the continuum of language contexts existing in the community.

This article considers the social and historical development of English language teaching as it shapes current practice. My intent is not to examine language teaching as an isolated field, however, but to render it as an element of a broader sociopolitical and cultural landscape. Language teachers, like most other citizens, are becoming increasingly concerned about our role as individuals in issues such as the environment and the effects of technology on society, but we may be puzzled as to how our own work might relate to these global questions. This article begins to explore the nature of these connections, and its terrain may therefore seem unfamiliar, difficult to follow. It has been difficult for me to travel, and to interpret as well.

The article has two main sections: Part I considers the context of language teaching, including social, historical, technological and political dimensions, and a critique of current treatment of language relative to content in adult immigrant education. Part II argues for reconceptualization of the work of language teaching in response to interacting features characterizing a) expressed learner needs, and b) responsive instructional environments. Evidence supporting such an environmental model is derived from two studies concerning the learning situation of adult immigrant students in Edmonton (Ho, 1990) and Toronto (Hynes, 1987). 


\section{PART I}

\section{The Context of Language Teaching}

As a field of specialization, English language teaching has increased exponentially during the course of the twentieth century. Economic, political and technological developments which have given rise to the modern age have also led to greater and more sustained contact between peoples of the world, and language teaching has contributed to enabling such contacts. As well, movements of vast numbers of people through displacement and immigration, colonialism, the rise of international trade and the world-wide development of science and technology have created unparallelled demands for second and foreign language teaching to facilitate participation in expanded social, economic and technological spheres. Thus the expansion of English language teaching as a global phenomenon can be seen as more closely tied to objectives which are primarily political, economic and technical, than those which are purely linguistic or social.

The geographic, social and economic situation of learners across such a diverse field constitutes a challenge to those who would try to envisage language teaching as a unified field. Stern (1983), for example, opens Fundamental Concepts of Language Teaching with a chapter describing the characteristics of the field, identifying various dimensions of the language learning equation, and reviewing the range of expressions used to talk about language learning and learners. After clarifying a number of basic distinctions-L1/L2, second/foreign, intranational/international-Stern examines terms relating to "teaching" and "learning". As to the purposes for language teaching, Stern observes that

The various reasons which prompt such second language learning are familiar enough and need not be gone into here. The principal question is what provision must be made by society to help these individuals to learn the second languages needed. The answer to this question is what is meant by second language teaching. (p. 20)

In making such a statement, Stern appeals to the reader's own "common sense" understanding of why language teaching takes place, distancing his formal characterization of the work of language teachers from any analysis of its sociopolitical aspects. 
In his introduction to the Context of Language Teaching, Richards (1985) begins with an examination of language similar to that of Stern, but extends his treatment of the educational context to include policy questions.

Any subject, whether English, history, music, or religion enters the educational domain when it is found to be relevant to the demands and needs of a society. It is the task of educational and curriculum planners to examine these needs to determine what goals may be relevant to its educational system. (p. 4)

Richards, unlike Stern, places the rationale for decision-making concerning language teaching within a societal framework, acknowledging its situation as relevant to the goals of the system which contains it. Once assigned to educational planners, however, responsibility for policy decisions regarding language teaching is again dismissed as peripheral to the central work of language teachers.

A number of writers have questioned the characterization of English language teaching as a neutral practice (Auerbach \& Burgess, 1985; Judd, 1983; Phillipson, 1988; Cummins, 1989; Pierce, 1989; Pennycook, 1989; Ho, 1992), providing evidence from diverse areas to support their arguments. Auerbach and Burgess (1985) are concerned with the situation of adult immigrants to North America; Cummins (1989) writes about the situation of cultural minority children in American schools; Phillipson (1988) considers the implications of English language teaching in the international community; Pierce (1989) is concerned with political consequences of a populist movement for "People's English" in South Africa. That such divergent concerns can be seen to coalesce around the teaching of English demonstrates the pivotal role of language, or, more specifically, languages in the global community.

Many of these critiques of the treatment of language and education in society have successfully situated issues of educational practice directly within the economic and political structure of the social world as it has developed historically, locating the topic of language education within the interpretative framework of critical theory. Such analysis, however, has been criticized as inadequate by postmodern writers (Lyotard, 1984; Mouffe, 1988; Popkewitz, 1988; Giroux, 1991): it is founded on a static theory of society and history and cannot respond to increasing levels of social and technological complexity which demand eminently creative responses. 
But where does such creativity come from? Jerome Bruner (1986, p. 132) argues that it is in language, that "language not only transmits, it creates or constitutes knowledge or reality". If, indeed, the ideologies and patterns of the present are unsuitable as models on which to construct a future with less destructive notions of economy, technology and society, we must begin to consider, challenge, and learn to play with the meanings of our institutions, including education, responsive to the culture in which we live. As Canadian society itself changes to increasingly challenge notions of homogeneity relative to culture, race and class, the shape of appropriate education for our people becomes problematic, an authentic unknown.

Given such a challenge, how are educators to conceive of their work? If an historical situation of language teaching is inadequate for the purposes of planning, how can teachers begin to think about what it is that they are doing/what it is that students are doing? Questions such as these call teachers to explore the inhabited world of language/learning (learning, learning language, learning second language). They proceed from an understanding that second language learning and teaching take place in the fundamentally untidy context of society, a place where learner priorities are often shaped as much by economic goals as by any interest in the language of instruction, where some languages are perceived as barriers while others are lauded as tools.

\section{Language Teaching is Technology}

The twentieth century has been the stage for a proliferation of theories of language structure and teaching methodologies which share many features, hence a similar ideology, with more obviously mechanistic technologies. The treatment of language as behaviour which can be conditioned through application of suitable stimuli-the audiolingual method, Chomsky's conceptualization of a "language acquisition device" in humans (Chomsky, 1968), and accelerating development of theories of language based on computer models and their complementary teaching methodologies exemplify the treatment of human experience as parallel to (and ultimately comparable with) mechanical form and function.

Bookchin (1982) traces the concurrent rise of the technical and technique in modern times, revealing their underlying unity of form and purpose, showing that it is the human mind that gives rise to social and political structure, creating, by extension, the culture of the machine. Technical thinking is evident in language teaching. 
Consider how closely the development of a teaching methodology resembles the process of design in a technology such as the computer. A teaching method is a mental construct embodying a particular theory of language. It identifies appropriate strategies (programs) and describes the shape of language teaching goals (outcomes). Similarly, a computer is a mechanical embodiment of engineering theory, a system for which methodologies (programs) have been tailored to manage and share information. To participate in computer technology, one must have some introduction to the culture and language of the machine, and this is provided either through classroom instruction or through individual study.

Environmentally speaking, technologies such as the computer can be shown to have both positive and negative effects for, while computers help in fields like medicine with applications such as diagnostic imaging and life monitoring systems, the proliferation of waste paper, obsolete machinery and public collection of private information constitute more negative impacts of such technology. But what about the impact of "mental" technologies such as teaching methods? Do they also have an impact on the environment? In fact, language and the technology of language education do affect the character of the environment in terms of colonialism, international trade, technology transfer, and social interaction.

\section{The Context of Language Teaching}

Just as language teaching has an effect on the character of the natural environment, so too does context shape the curriculum of language teaching. This statement emerges from an understanding that it is the actuality of international trade, immigration and adaptation, international education or science and technology which makes language teaching both possible and necessary. Curriculum is derived from the intents of policy makers, those who would make programs available. Johnson $(1989$, p. 3) examines the decisionmaking framework of the language curriculum and describes policy makers as those responsible for programs, whether they be directors of private language schools or government bureaucrats. It is the role of policy makers to translate the goals and values of their constituency into programs.

Second language teaching is an aspect of education. This simple statement reflects an essential understanding of teachers and theorists (Mohan, 1986; Brinton, Snow \& Wesche, 1989; CelceMurcia, 1989; Benesch, 1988b) who study the relationship of second 
language and content learning. Mohan (1986, p. 1) describes the relationship of language and content thus:

A language is a system that relates what is being talked about (content) and the means used to talk about it (expression). Linguistic content is inseparable from linguistic expression.

In an integrated learning context, however, language does not act merely as a relating tool in the instrumental way that a spoon relates to soup. Language shapes content and content shapes language. One's language is one's voice (Hymes, 1983, p. 190). Culture is shared and expressed through language. Ideas are created through language.

In spite of the centrality of language to issues of culture, expression and social participation, however, much of the professional training of ESL or ELT professionals continues to project a narrow linguistic, psychological and methodological focus to the work. "It pays little attention to international relations, development studies, theories of culture or intercultural contact, or the politics or sociology of language or education" (Phillipson, 1988, p. 348). The context of use is estranged from classroom practice: its structure and function are often parodied through methodologies which disconnect communication from community.

\section{Immigrants in the Context of Adult Education}

As an educator and researcher, I seek to interpret language teaching practice within a framework which recognizes the integrity and aspirations of a diverse population of learners and the emancipatory possibilities of education. My work has principally concerned the adaptation of immigrants and refugees within Canadian society and the social change inherent in integrating large numbers of culturally-diverse people within an evolving multicultural society. As such, I understand that increasing the cultural diversity of a community does not just diffuse the character of the dominant culture, nor is it additive to it. Instead, the culture of the whole is profoundly affected by the inclusion of minorities (Redfield, 1955, p. 149).

If we consider the range of needs for content among adult immigrants (Ho, 1990; Hynes, 1987)), including community participation and citizenship, vocational training, professional requalification, and academic upgrading, the place of language becomes paramount. Canada Immigration acknowledges this when it states that "learning 
to communicate in one of Canada's official languages is a prerequisite for integration" (Canada. Immigration, 1990, p. 14). The discourse of linguistic prerequisites set within an already official bilingual framework, however, begins to disintegrate upon closer inspection. What is meant by linking language with integration in a cause and effect relationship? Does it convey an expectation that immigrants must first learn English or French before they can integrate? The Canadian government's position is that integration of any description is unlikely without proficiency in an official language. They provide no documentation, however, to show how proficiency in an official language will facilitate this desired goal. The complex nature and variety of modes of integration remains unaddressed.

Schermerhorn (1970) describes the potential outcomes of cultural contact almost as a continuum, ranging from completely enclosed (adjustment within group only) to completely assimilated (adjustment to majority values). There is diversity in the possibilities of ways and destinations imagined and actualized by cultural groups. It is when the texture of this diversity is not addressed, however, when homogeneity of educational purpose is assumed and structured into programs, that community responses to immigrant needs are not integrative, that is, responsive to the impact of change on all parts of the whole, but rather assimilationist, placing the onus for change on minority learners in order to maintain the standards and traditions of the educational system.

This observation, while pertaining to culture generally, should also be interpreted as it relates to language and content learning among immigrants. Actual educational issues among adult immigrants may be shown to relate more directly with content than with language. In her study for George Brown College in Toronto, Maureen Hynes (1987, p. 119) investigated minority community perceptions regarding the accessibility of programs. She received considerable feedback suggesting "the need to revise existing College programs and to develop new programs in response to the educational and training needs of diverse racial and cultural communities in Metro Toronto". A variety of formats for provision of content were recommended, including employment-specific ESL and literacy training, and training programs offered in bilingual or even monolingual (mother tongue) settings.

Ho (1990), in a study conducted in Edmonton, assessed the issue of access to content (i.e. education) by immigrants from the various perspectives of adult ESL programmers, adult education programmers, funders and settlement agencies and found that a 
major impediment to documentation was the relative invisibility of the issues: in content-related matters, ESL programmers tended to defer to mainstream adult educators while the mainstream programs indicated that, in their view, ESL was prerequisite to content learning. Language and content, as they pertain to immigrants, were indeed linked in the thinking of all of the educators surveyed. Unfortunately, the perceived link was identified mainly as residing within immigrants themselves and not widely translated into facilitative linking or bridging programs.

In comparing the findings of Hynes (1987) and Ho (1990), the vastness of the communication gap separating adult immigrants and the educational community becomes readily apparent. Immigrants want and need access to content via a variety of language approaches while governments and institutions tend to think of ESL as education for immigrants. Content is the realm of mainstream adult education (colleges, universities, technical schools) and is generally available to all on an equal opportunity basis. Notions such as "equal opportunity", however, fail under close inspection because they do not have the effect of equalizing access by all groups.

Recognition of communicative diversity has tended to be interpreted educationally with the lowering of standards (Furnborough et al., 1982; Shor, 1986). This narrow view of language, however, has been strongly countered by researchers such as Jim Cummins (1986, p. 21), who recommends "incorporation of minority languages and cultures into the school program" as a strategy to promote minority integration and advancement. The integrative relationship of language and learning is also widely recognized. In fact, much of the original work with language and content was done in K-12 classrooms, where the accessibility of language and content by all learners has more generally been addressed by educators (Early, Mohan \& Hooper, 1989; Handscombe, 1989; Heath, 1983). Mohan (1986) and WongFillmore (1982), among others, have documented some of the ways in which content learning supports second language learning and vice versa.

\section{Language and Content}

Communicative approaches developed in Europe and North America in the 1970s and 1980s (van Ek \& Alexander, 1977; Munby, 1978; Canale \& Swain, 1980) successfully raised awareness of the intrinsic functionality of language, but did not attempt to 
actually connect this functionality with real life experience. Many ESL teachers who followed the Communicative Approach spent (and still spend) hours trying to reproduce (photocopy) the current state of the world via brochures, forms, and the inevitable roleplay exercises, in order to duplicate from it a "functional" environment for language learning. Subsequent approaches to the teaching of language and content have drawn a lot of attention among immigrant educators because student educational and employment goals are, more often than not, within the societal mainstream. In fact, the impetus for the reconciliation of language and content arises from a growing awareness within the field of language teaching of the need to exploit learners' communicative environments generally.

The theoretical connection of communicative language teaching with actual content, however, has vastly extended the possibilities of the Communicative Approach: it has moved language and learning from the segregation of ESL into the mainstream of education. At the same time, its conceptualization appears to rise in a variety of forms. Mohan (1986, p. 18) observes that "language learning in the communicative environment of the content classroom furthers the goals of language teaching by offering a context for language", highlighting the quality of the communicative environment made possible in a content-based class. Brinton, Snow and Wesche (1989, p. 2) note that "in a content-based approach, the activities of the language class are specific to the subject matter being taught, and are geared to stimulate students to think and learn through the use of the target language", allowing that content gives shape to the language curriculum. Chamot and O'Malley (1987, p. 228) adopt a more mechanistic view of the relationship between language and content, focussing on "English as a tool for learning subject matter". Benesch (1988a), in contrast, provides a more holistic view, acknowledging both language and learner experience as mediating factors in the educational process:

ESL instruction in higher education should mediate between students' previous experiences with English and formal learning and the new linguistic, cognitive, social and cultural demands of studying content in an American college in the target language." (p. 2)

Conceptualizations of the relationship between language and content appear to represent a continuum from mechanistic to holistic, with no preeminent view emerging as yet. 


\section{Contextualizing Language Teaching}

Language teaching is not alone, however, in the movement toward the social contextualization of theory and practice. The past twenty years have given rise to parallel movements in both the social and natural sciences. The philosophy of critical theory has provided a comprehensive critique of the ideology of capitalism and has stimulated both social and natural scientists to search for constructive alternatives to the reductionism characterizing much empirical research. In psychology, there is some movement toward a view of the world in socio-historical-environmental context, as a process of social interchange-people in the world-with an emphasis on the possibility of effecting social change (Gergen, 1985; Saegert, 1987; Stokols, 1990). Theorists in the philosophy and sociology of education (Giroux \& Simon, 1988; Illich, 1983; Shor, 1986; Freire, 1989) write about schooling which responds to the lived needs of the people in the community and criticize the reluctance of much of mainstream education to relinquish abstracted notions of "knowledge" and "culture." The thread which weaves these ideas together is the conceptualization of human experience as interactive within the social environment and the world. That this movement should evolve concomitant with increasing public interest in the quality of the physical environment, in its preservation and enhancement is no coincidence. The same themes of relativism, social responsibility, continuity, conservation and possibility for alternatives recur across both movements.

It is the connected and interactive nature of the concept of environment which first prompted me to wonder about the context of language teaching within its broader social dimension. I reasoned, as had others before me, that since language teaching occurs at junctures between diverse groups throughout the world, its effect must be recognized as more than linguistic or social. This particular strand locates such work primarily in the sociopolitical sphere, as recently outlined by Pennycook (1989). Whether teachers are working with minority students, teaching internationally or teaching English as a foreign language in their own country, the selection of method or approach, the choice of materials and content, the power dynamics of teacher/student relations and even the location of the language program within the total educational structure have implications which far exceed classroom objectives. In the case of immigrant adult education in Canada, for example, current emphasis on the improvement of language training (Canada. Immigration, 1990) without addressing the fundamental, isolated 
location of most ESL programs can only serve to increase pressure on teachers and learners to perform, still in isolation. Where is the corresponding emphasis within the system on the role of mainstream adult education (ie. content) in adapting programs toward the needs of immigrant learners? There are examples such as the Polish Doctors Program (Toronto Board of Education) and the Trades and Occupational English Program in Alberta, but across the mainstream of adult education in Canada there appears to be little official recognition of language education within the broad framework of the educational continuum available to Canadian-born adults.

\section{Material Questions: The Content of Language Teaching}

Earlier in this paper, I described as an outcome of the Communicative Approach the reproduction of status quo sociopolitical relations between the linguistic majority and minorities through the manufacture and photocopying of communicative materials. This is unwittingly corroborated by Edelhoff (1981, p. 54) who, in writing about materials for communicative language teaching, notes that "displaying a foreign language in the teaching/learning situation is always a matter of reproduction, simulation and artifice". Given the generally isolated context of adult immigrant ESL within education and society, the photocopier mediates metaphorically as well as functionally. It reproduces representations of language, of society and social relations within society. Lacking access to any comprehensive body of content other than functions and notions of language, teachers have had to scramble to create this environment which simulates "real life" to prepare learners to use English communicatively.

This process of reproduction, while physical in its overt appearance as photocopies, videotapes, maps, and so on, has farreaching implications at the social level. If teachers and learners are using materials structured in another context, they are also experiencing the aspects of that context which led to the selection and development of those materials, including social class (materials used with immigrants and refugees may have originally been developed for tourists or for foreign students) and instructional purpose (students wishing English for professional practice may feel they are wasting time with communicative yet abstracted hypothetical situations, e.g. the desert island). The informational use of "reproductive technologies" may have the effect of distancing language teachers and learners from shared issues, needs and 
aspirations, that is, from the emerging content of everyday life. It encourages learners to use English to locate knowledge externally rather than to interactively participate in its creation.

\section{Language and Content and Education}

By examining the context of language teaching as interpreted both extensively (as an element of the continuum of content) and restrictively (in isolation from content), several characteristics of the language environment may be distinguished. These concern the treatment of relationships between:

1. Language and content-The relationship between language and content can be characterized in ways ranging from mechanistic to holistic. A mechanistic characterization is interpreted in views of language as a "tool", a prerequisite for other learning, a system of vocabulary and grammar. A holistic orientation is indicated by the acknowledgement of the interactivity of language and content and the possibility of each aspect being used to enhance the other;

2. Language teaching and the sociocultural-political context -Language teaching can be treated in ways ranging from theoretical isolation to conceptual integration within a much broader educational arena, enmeshed socially, politically and economically in issues as broad as international migration, immigration and national development, international trade, the development of science and technology;

3. Language learning and the educational context-Second language or foreign language learning can variously be conceived of as an enterprise segregated from content learning or as situated environmentally, that is, relative to the broader personal and educational goals of learners.

This final point situates the central problem of this paper. Even though many adult learners will claim that learning English is, in itself, a priority, their statements may be more indicative of an urgent need to clarify and articulate routes to their intended goals or even a desire to please teachers and other decision-makers. Second language proficiency may not be a primary goal for a great number of learners, nor is it a possibility for all second language learners. Many learners may seek only enough English for 
instrumental use (Lambert, 1967). Their interest in language learning is tied largely to what they will be able to do with this new information. For some others, and this is a serious consideration among immigrants and refugees, the process of language learning is long and slow and the progress made in existing programs hardly worth the effort. Such learners may have limited literacy and/or education in their first language, they may have extensive family responsibilities, they may have memory difficulties due to torture or other trauma (Canadian Task Force on Mental Health Issues Affecting Immigrants and Refugees, 1988), or they may simply not be good language learners. In any case, the outcome is the same. In a mechanistic educational system which places language and content in sequence, individuals can spend enormous amounts of time in ESL classes with little demonstrated progress. Yet they may be denied access to content, not only because of a lack of personal competence (Hymes, 1979), but English proficiency. As Hymes remarks, "liberality with regard to religion and sex does not seem to extend to speech" (p. 37). Policy makers and adult education programmers in a culturally diverse society such as Canada's must acknowledge the continuous nature of the language environment to facilitate access to content by all. Proficiency in an official language may be a possibility for many immigrants, but it is the totality of all languages in Canada which is our shared reality.

\section{PART II}

\section{Toward a Social Ecology of Language}

How we treat the language education of adult immigrants depends on how we view their languages, as well as official languages, as elements of a shared linguistic environment. A denial of linguistic diversity in adult education (and society in general) in the face of the actuality of multilingualism reveals much about the official Canadian ideology of language. To discriminate in the provision of education (content) on the basis of competence in English (language) rather than personal competence reveals a systemic linguicism. This is defined by Skutnabb-Kangas (1988, p. 13) as "ideologies and structures which are used to legitimate, effectuate and reproduce unequal division of power and resources (both material and non-material) between groups which are defined on the basis of language (on the basis of their mother tongues)." Adult education, by virtue of its position in the development and education of citizens, has the possibility of promoting linguicism 
(i.e. providing education in English only) or of encouraging its demise by recognizing the place of minority languages within its framework.

With regard to the application of existing language and content theory to the particular situation of immigrants in adult education, then, a number of assumptions concerning the character of the environment and teaching practice should be examined. The first assumption is an unspoken one, that language teaching is value-free. There is little written about varieties of discourse, selection of content, and the implications of each for social and economic participation by immigrants, and this is revealed in the absence of such discussion in the literature of language and content. Both language and content teaching, however, inhere particular relationships between the teacher and her learners, as well as particular learning outcomes. Bowles and Gintis (1986, p. 160) observe: "The tools of discourse facilitate practices, while in part constituting them through the forms of bonding and division they foster and through the limitations they place on the expression of goals and means of their attainment", paraphrasing Marshall McLuhan's now famous aphorism "The medium is the message". The educational environment is essentially political, involving, among other things, the selection of content, the stance taken vis $\grave{a}$ vis the political and economic system, and the situation of the learner in decision-making.

A second assumption which seems to be made about language and content is that only one language, the new language, is used to convey content. A basic learner background of English or French is also generally assumed. Use of other languages or combinations of languages is seldom discussed. This position is a premise for Brinton, Snow and Wesche $(1989$, p. 2$)$, "the focus for students is on acquiring information via the second language and, in the process, developing their academic language skills"; Benesch (1988a, p. 2), "they [second language learners] need practice in listening to, speaking, writing, and reading English in an academic context to ensure their continued membership in the community"; and Friedenberg and Bradley (1988, p. 7), "students should have an opportunity to acquire a general knowledge of English before attempting to learn a trade in a vocational school". This assumption is posited upon a static notion of the educational environment in which the relationship between the learners' native language and the "target" language is seldom considered relative to content or community. 
A third assumption has to do with the scope of models for language and content teaching and their independence of any potentially-related social or educational environment; the language teacher reaches out for content and the language classroom becomes the content environment. In an article describing three types of language and content models, Marianne Celce-Murcia (1989) gives practical advice for selecting an approach. Given a new group of students in an ESL program, she advises teachers to get as complete a picture of the students as possible. "If good biodata are collected when this instrument is administered, then we also have the social, ethnic, and educational background of our learners" (p. 6). This is good general advice for language teachers, but Celce-Murcia includes no consideration of matching the students' profiles with one of the educational environment, or of documenting the points of dynamic intersection between the institution (instructional purpose) and language communities (personal goals) so that these could most effectively be exploited for the benefit of the students.

A further assumption found in the literature of language and content concerns the location of models for language and content teaching. For the most part, these are firmly and uniquely established in the traditions of language teaching. There is very limited effort being made by most content area teachers, although those that have become involved have made a significant contribution in language teaching. Without increased cooperation with content area specialists, though, how can language teachers anticipate their eventual involvement (which we already assume) as partners in education? What kinds of accommodation on the part of mainstream educational environments are being made to respond to the particular content needs of immigrant learners? If the system as a whole remains inflexible, intact, the focus of change will always be upon the learners.

What must be acknowledged by language teachers, content teachers, language and content teachers, decision makers and by diverse societies generally, is the continuous nature of the language environment in a diverse society. Adherence to a view of content as accessible only through English, or through English or French, ignores the sometimes fluid/sometimes discontinuous character of the language environment. No amount of second language programming, counselling or prodding is going to alter the fact that people learn in a variety of ways and that a variety of responses to adaptation needs should accordingly be made. If our purpose is truly integrative, we should develop educational opportunities which reflect shared values (i.e. related to personal goals) rather than an 
ideology of domination through monolingualism (or official bilingualism).

A framework for considering language and content relationships within the context of a culturally and linguistically-diverse society is described in Figure 1 (Approaches to Content in Multilingual Settings: A Conceptual Framework). The figure itself integrates two dimensions-Instructional Environment and Instructional Focus-which interact through language (environment) and content (focus). The Instructional Environment envisaged is an inclusive one, extending from language sheltered (instruction in minority languages exclusively) settings to the segregated multicultural environment (multicultural classes for immigrants segregated from mainstream instruction) to the integrated multicultural environment (immigrants are integrated into mainstream multicultural classes). The vertical dimension represents the instructional range from an exclusive content focus to an exclusive language and social focus. This dimension concerns the broad range of personal goals, skills and needs which are represented among immigrants. The nature of this dimension includes consideration of particular learning needs: literacy needs, the special needs of seniors, and needs for community development and social participation.

The interaction of these two dimensions provides a means of conceptualizing a range of possible strategies for combining language and content to respond to documented (Hynes, 1987; Ho, 1990) learner needs and goals. Generic ESL programs occupy only a very small area in terms of the actual range of needs expressed and the nature of the environmental continuum, yet they currently make up, by far, the majority of programs offered for adult immigrants throughout Canada. This is a serious concern for, while such programs are of some use, their position, by virtue of their situation within the overall environment should be a transitional one. Generic ESL does not have a strong content focus, nor a strong integrative orientation. It is a kind of "middling" model which is useful for initial orientation for some people, but it has no specific purpose related to any particular employment, social or educational context. Its focus is isolating in terms of physical location of classes as well as communicative opportunities.

Of greater interest are the possibilities of approaches at the both ends of the environmental dimension. At one end, programs which are language sheltered (i.e. conducted in learners' primary languages) and have a language focus are available for many children through Heritage Language Programs in Canada. The possibilities of sheltered programs for adults, however, are immense 


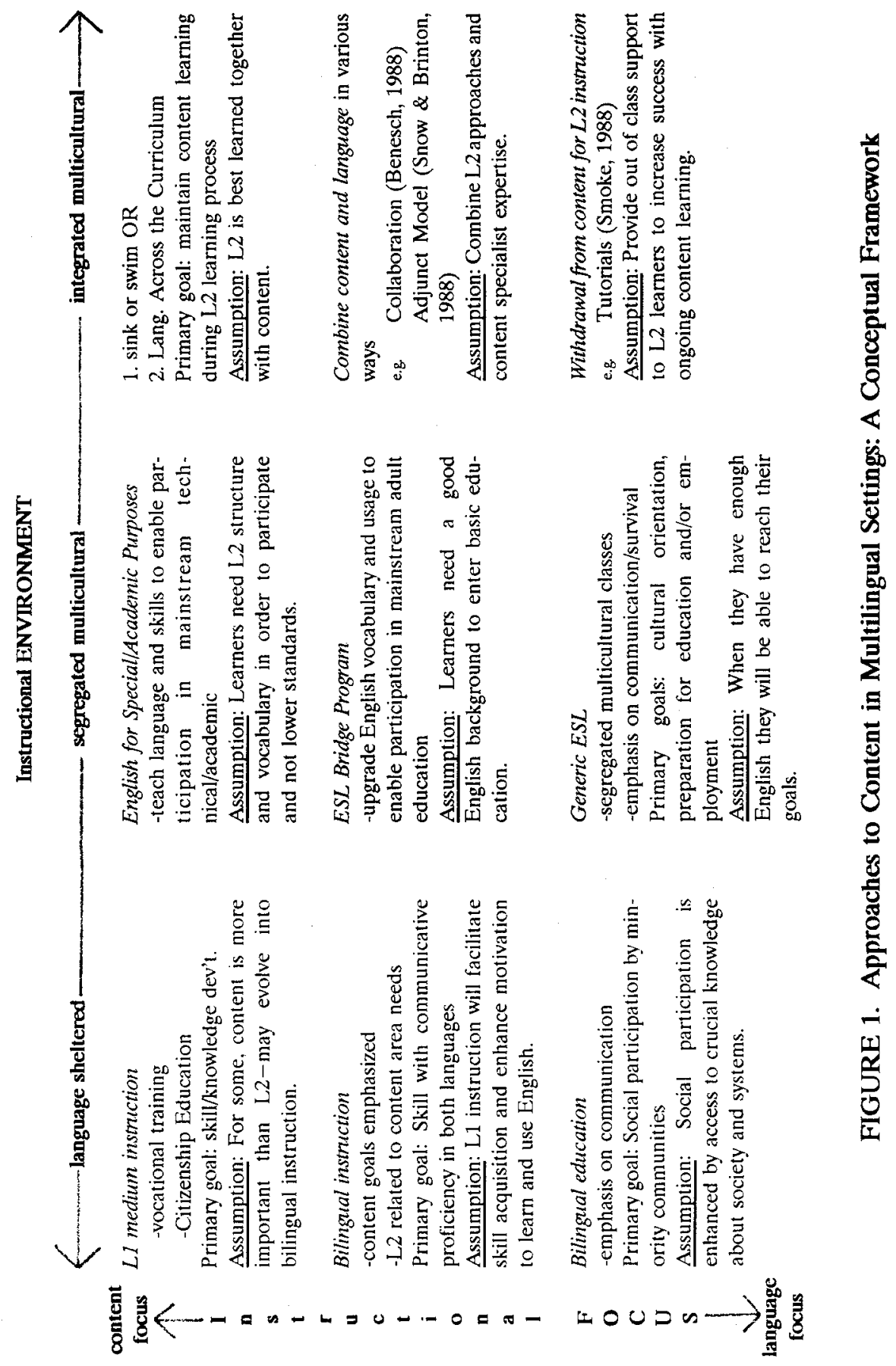


but relatively untried, spanning the range of the instructional focus continuum. Many immigrants and refugees could access skill training and community systems at an earlier stage of their adaptation if programs were available in their languages. This is a particularly important consideration among groups with limited literacy or limited education for whom traditional ESL classes are often not appropriate or successful. Provision of content instruction in minority languages should be considered as a practical response to the needs of individuals who clearly will require special help with language and employment over a long period of time. This is particularly apropos to the situation of many refugee adults who arrive from societies such as Cambodia and Ethiopia which are culturally and vocationally very different from Canada. Provision of first language environment instruction for training and understanding Canadian society is an acknowledgement of the personal competence and integrity of members of all communities. An individual who feels secure in his or her expression of personal competence is more likely to desire communication with other cultural groups and to sense a belonging within Canadian society.

Programs at the integrated multicultural end of the continuum are characterized by their location within mainstream adult education. Language learners study together with native speakers in a monolingual setting with varying degrees of assistance. One possible interpretation of content focus end of the instructional dimension here is the traditional "sink or swim" approach (really a non-approach) in which the learner is left to figure out the language and the lesson for him or herself. It is curious that the "sink or swim" method occupies a similar area of the framework as the more thoughtful language across the curriculum, but this is because of their shared orientation toward integration and content. These two approaches differ dramatically along a third dimension which concerns the language awareness of the educational community.

Movement from content focus toward language focus in integrated settings should result in increased intervention by second language teachers to support effective learning. This should not be interpreted as a negative aspect of the transition but rather a way, again, to conceptualize the effect and location of various instructional strategies relative to learner goals. The tutorial system described by Hirsch (1988), for example, seems a very effective way to support content area learning. It matches groups of ESL learners in content area courses with tutors who assist with the writing process and approaches to content, and allows for an ongoing series of quick lessons directly related to the language 
needs of the content program. The approach selected will depend on the characteristics of the particular groups of learners (CelceMurcia, 1989) and the characteristics and possibilities of the instructional environment.

\section{An Environmental Approach to Language Planning}

The conceptual framework presented has evolved through my increasing concern about adult immigrant education from two perspectives, that of teacher and of citizen. As a teacher, I am concerned that opportunities available to my students are optimal, given available financing for immigrant education and the state of the art of language teaching theory and practice. I do not feel, however, that current provisions for programming are responding to the lived needs of adult immigrants in Canada. There are too many "ESL students" who want training, professional upgrading and qualification, basic education, or simply access to information who are discounted by mainstream educational programs, put off by artificial language requirements and who disappear into the silence of work and life without ever letting a teacher know why. Language (both English and minority) must be considered within a content framework; language and content must be considered within a social framework.

I say this as well as a citizen. The pressures which face humanity at the end of the twentieth century are immense but the need for imagination is greater. In a democratic society, issues such as the environment, technology, social and political change should be concerns involving all citizens. In a culturally-diverse democratic society such as Canada's, the shape of the body politic itself must become curriculum as we struggle for ways to acknowledge the differences among us (Mouffe, 1988). Canada cannot be considered a progressive nation if we encourage the immigration of large numbers of people without conceptualizing, in an inclusive way (we and they together as we), the impact of such change on all our systems, including adult education. Language cannot be treated as an add-on as ESL is treated now. It is doled out, meted out, measured and reported, but it is not, as an enterprise, responsive to the integrative goals of immigrants and refugees. Meaningful curricular issues are obscured by our preoccupation with difference in language. These concern the possibility of participation and the sharing of our collective wealth of skills and talents.

That is why it is essential for us, as teachers and citizens, to begin questioning the assumptions on which language teaching theory is 
currently based, to begin to engage with immigrant students as participant in Canadian life and not merely as spectators. Language teaching is not apolitical; it is situated by virtue of its physical location (usually isolated), its content (or lack thereof) and its participants. Content is not only accessible in English. There are many skilled teachers who have immigrated together with others from their country. There are many learners who could benefit from minority language or bilingual content instruction for training and for community participation. Immigrant learners should not be the only aspect of the educational environment which is subject to change. The proportion of immigrants and refugees who are in Canada or are coming to Canada-about $23 \%$ of our population total, according to a recent technical report (Fallick, 1991, p. 12) - can and should have a significant impact on the entire system of adult education. The environment of education must adapt to respond to the diverse needs of the people in the community. Finally, language and content as a concern cannot remain the exclusive property of language teachers. Language is as much an element of content as content is of language. The environment of this issue is not language, but society.

\section{THE AUTHOR}

Laura $\mathrm{Ho}$ is a doctoral candidate in Education at the University of Alberta. She has varied experience working with immigrants as a classroom teacher, teacher resource person, administrator, and educational counsellor and researcher. Her current work concerns education and the process of change in the experience of immigrants: immigrants and the process of change in adult education. 


\section{REFERENCES}

Auerbach, E. \& Burgess, D. (1985). The hidden curriculum of survival ESL. In I. Shor (Ed.) Freire for the classroom. Portsmouth: Heinemann.

Benesch, S. (Ed.) (1988a). Ending remediation: Linking ESL and content in higher education. Washington, D.C.: TESOL.

Benesch, S. (1988b). Linking content and language teachers: Collaboration across the curriculum. In S. Benesch (Ed.) Ending remediation: Linking ESL and content in higher education. Washington, D.C.: TESOL.

Bookchin, M. (1982). The ecology of freedom. Montreal: Black Rose Books.

Bowles, S. \& Gintis, H. (1986). Democracy and capitalism: Property, community, and the contradictions of modern social thought. New York: Basic Books.

Brinton, D., Snow, M. \& Wesche, M. (1989). Content-based second language instruction. New York: Newbury House.

Bruner, J. (1986). Actual minds, possible worlds. Cambridge: Harvard University Press.

Canada. Immigration. (1990). Backgrounders to the annual report to parliament: Immigration plan for 1991-1995. Ottawa: Minister of Supply and Services.

Canadian Task Force on Mental Health Issues Affecting Immigrants and Refugees. (1988). After the door has been opened: Mental health issues affecting inmigrants and refugees in Canada. Ottawa: Health and Welfare Canada.

Canale, M. \& Swain, M. (1980). Theoretical bases of communicative approaches to second language teaching and testing. Applied Linguistics, 1(1), pp. 1-47.

Celce-Murcia, M. (1989). Models for content-based curricula for ESL. CATESOL Journal, November, pp. 5-16.

Chamot, A. \& O-Malley, J. (1987). The cognitive academic language learning approach: A bridge to the mainstream. TESOL Quarterly, 21(2), pp. 227-249.

Chomsky, N. (1968). Language and mind. New York: Harcourt, Brace and World.

Cummins, J. (1986). Empowering minority students: A framework for intervention. Harvard Educational Review, 56(2), pp. 18-36.

Cummins, J. (1989). Empowering minority students. Sacremento, CA: California Association for Bilingual Education.

Early, M., Mohan, B. \& Hooper, H. (1989). The Vancouver School Board language and content project. In J. Esling (Ed.) 
Multicultural education and policy: ESL in the 1990's. Toronto: OISE.

Edelhoff, C. (1981). Theme-oriented English teaching: Text varieties, media, skills and project-work. In C. Candlin (Ed.) The communicative teaching of English: Principles and an exercise typology. Singapore: Longman.

Fallick, A. (1991). People, jobs and immigration: $A$ study of Canada's future workforce. Vancouver: Laurier Institute.

Freire, P. (1989). Pedagogy of the oppressed. New York: Continuum.

Friedenberg, J. \& Bradley, C. (1988). A handbook for vocational English as a second language. Bloomington, Ill.: Meridian.

Furnborourgh, P. , Jupp, T., Munns, R. \& Roberts, C. (1982). Language disadvantage: Breaking the cycle of majority perception. Journal of Multilingual and Multicultural Development, 3(3), pp. 247-266.

Gergen, K. (1985). The social constructionist movement in modern psychology. American Psychologist, 40(3), pp. 266-275.

Giroux, H. (1991). Postmodernism as border pedagogy: Redefining the boundaries of race and ethnicity. In H. Giroux (Ed.) Postmodernism, feminism, and cultural politics: Redrawing educational boundaries. Albany, NY: State University of New York Press.

Giroux, H. \& Simon, R. (1988). Schooling, popular culture, and a pedagogy of possibility. Journal of Education, 170(1), pp. 9-26.

Handscombe, J. (1989). Mainstreaming: Who needs it? In J. Esling (Ed.) Multicultural Education and Policy: ESL in the 1990's. Toronto: OISE Press.

Heath, S.B. (1983). Ways with words: Language, life and work in communities and classrooms. New York: Cambridge University Press.

Hirsch, L. (1988). Language across the curriculum: A model for ESL students in content courses. In S. Benesch (Ed.) Ending remediation: Linking ESL and content in higher education. Washington, DC: TESOL.

Ho, L. (1990). Survey of immigrant participation in the adult education community of Edmonton. Unpublished Master's thesis. Edmonton: University of Alberta.

Ho, L. (1992). Both sides now: Toward a multicultural framework for adult education in English-speaking Canada. In B. Burnaby \& A. Cummings (Eds.), Socio-political aspects of ESL. Toronto: OISE. 
Hymes, D. (1979). Sapir, competence, voices. In C.J. Fillmore, D. Kempler \& W. S-Y. Wang (Eds.), Individual differences in language ability and language behavior. New York: Academic Press.

Hymes, D. (1983). Report from an underdeveloped country: Toward linguistic competence in the United States. In B. Bain (Ed.) The sociogenesis of language and human conduct. New York: Plenum.

Hynes, M. (1987). Access to potential: A two-way street. (An educational and training needs assessment of Metro Toronto's diverse racial and cultural communities). Toronto: George Brown College.

Illich, I. (1983). Deschooling society. New York: Harper \& Row. Johnson, R. (1989). A decision-making framework for the coherent language curriulum. In R.K. Johnson (Ed.) The second language curriculum. Cambridge: Cambridge University Press.

Judd, E. (1983). TESOL as a political act: A moral question. In J. Handscombe, R. Orem \& B. Taylor (Eds.), On TESOL '83. Washington, DC: TESOL.

Lambert, W. (1967). A social psychology of bilingualism. Journal of Social Issues, 23(2), pp. 91-109.

Lyotard, J. (1984). The postmodern condition. Minneapolis: University of Minnesota Press.

Mohan, B. (1986). Language and content. Reading, MA: AddisonWesley.

Mouffe, C. (1988). Radical democracy: Modern or postmodern? In A. Ross (Ed.), Universal abandon? The politics of postmodernism. Minneapolis: University of Minnesota Press.

Munby, J. (1978). Communicative syllabus design. Cambridge: Cambridge University Press.

Pennycook, A. (1989). The concept of method, interested knowledge, and the politics of language teaching. TESOL Quarterly, 23(4), pp.589-618.

Phillipson, R. (1988). Linguicism: Structures and ideologies in linguistic imperialism. In T. Skutnabb-Kangas \& J. Cummins (Eds.) Minority education: From shame to struggle. Clevedon, UK: Multilingual Matters.

Pierce, B. (1989). Toward a pedagogy of possibility in the teaching of English internationally: People's English in South Africa. TESOL Quarterly, 233(3), pp. 401-420.

Popkewitz, T. (1988). Culture, pedagogy and power: Issues in the production of values and colonialization. Journal of Education, 170(2), pp. 77-90. 
Redfield, M. (1955). The little community. Chicago: University of Chicago Press.

Richards, J. C. (1985). The context of language teaching. Cambridge: Cambridge University Press.

Saegert, S. (1987). Environmental psychology and social change. In D. Stokols \& I. Altman (Eds.), Handbook of environmental psychology. New York: John Wiley \& Sons.

Schermerhorn, R. (1970). Comparative ethnic relations: A framework for theory and research. New York: Random House.

Shor, I. (1986). Culture wars: School and society in the conservative restoration 1969-1984. Boston: Routledge \& Kegan Paul.

Skutnabb-Kangas, T. (1988). Multilingualism and the education of minority children. In T. Skutnabb-Kangas \& J. Cummins (Eds.), Minority education: From shame to struggle. Clevedon, UK: Multilingual Matters.

Smoke, T. (1988). Using feedback from ESL students to enhance their success in college. In S. Benesch (Ed.), Ending remediation: Linking ESL and content in higher education. Washington, DC: TESOL.

Snow, M. \& Brinton, D. (1988). The adjunct model of language instruction: An ideal EAP framework. In S. Benesch (Ed.), Ending remediation: Linking ESL and content in higher education. Washington, DC: TESOL.

Stern, H.H. (1983). Fundamental concepts of language teaching. Oxford: Oxford University Press.

Stokols, D. (1990). Instrumental and spiritual views of peopleenvironment relations. American Psychologist, 45(5), pp. 641-646.

van Ek, \& Alexander, L. (1977). Systems development in adult language learning: Waystage. Strasbourg: Council for the Cultural Co-operation of the Council of Europe.

Wong-Fillmore, L. (1982). The language learner as an individual: Implication of research on individual differences for the ESL teacher. In M. Clarke \& J. Handscombe (Eds.), On TESOL ' 82. Washington, DC: TESOL. 